\title{
TV/Series
}

18 | 2020

Séries et espace

\section{Where the physical world meets the digital world: representations of power structures and cyberspace in television series set in New York}

Julie Ambal and Florent Favard

\section{(2) OpenEdition}

Journals

Electronic version

URL: http://journals.openedition.org/tvseries/4623

DOI: $10.4000 /$ tvseries.4623

ISSN: 2266-0909

Publisher

GRIC - Groupe de recherche Identités et Cultures

Electronic reference

Julie Ambal and Florent Favard, «Where the physical world meets the digital world: representations of power structures and cyberspace in television series set in New York», TV/Series [Online], 18 | 2020, Online since 15 September 2020, connection on 08 December 2020. URL : http://

journals.openedition.org/tvseries/4623; DOI : https://doi.org/10.4000/tvseries.4623

This text was automatically generated on 8 December 2020 .

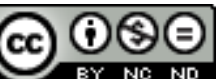

TV/Series est mis à disposition selon les termes de la licence Creative Commons Attribution - Pas d'Utilisation Commerciale - Pas de Modification 4.0 International. 


\title{
Where the physical world meets the digital world: representations of power structures and cyberspace in television series set in New York
}

\author{
Julie Ambal and Florent Favard
}

1 Following a succession of establishing shots over New York City, the camera gives us a close-up of a young, blonde woman sitting on a train arriving at Grand Central Station. A mysterious voice-over starts as she goes through the crowded building:

GOSSIP GIRL. Hey, Upper East Siders, Gossip Girl here. And I have the biggest news ever. One of my many sources, Melanie91, sends us this: "Spotted at Grand Central, bags in hand, Serena van der Woodsen".

2 Another young woman crosses Serena's path and takes a photo of her with her phone. Gossip Girl continues:

GOSSIP GIRL. Was it only a year ago our "it-girl" mysteriously disappeared for "boarding school"? And just as suddenly, she's back. Don't believe me? See for yourselves. Lucky for us, Melanie91 sent proof. Thanks for the photo, Mel.

Gossip Girl (The CW, 2007-2012), a television series focused on the Upper East Side golden youth, makes it clear from its first opening scene that no protagonist can escape the grasp of the eponymous blogger and their ${ }^{1}$ network of informers looking for the latest gossip. It also illustrates a gradual shift in storytelling, as devices such as smartphones and computers are becoming a common property, and as the digital world is taking up increasing space in our daily lives through internet, and especially social media. Contemporary works of fiction must deal with the same, dramatic evolution we face in the real world, mainly the fact that we are now all equipped with high resolution cameras and microphones and have access to unlimited knowledge ${ }^{2}$ and entertainment, while at the same time our private lives are more threatened than ever before through state-sponsored mass surveillance and obscure use of our data by private companies every time we visit a website or use an app. In a fascinating and chilling twist, the world we live in and the stories we tell about it have come to match 
the one envisioned by a subgenre of science fiction emerging in the 1960s and 1970s, namely cyberpunk, questioning, in near-futures, the correlation between hightechnology, virtual environments, cyberspace, artificial intelligence on the one hand, and social inequality, corporationism and dystopia on the other. The digital world is slowly infiltrating the physical world, with inevitable and irreversible effects on our culture, politics and economy.

Throughout this paper, we want to examine the socio-cultural and political aspects of the confrontation between the digital and the physical world in contemporary television series, by selecting four works of fiction: the aforementioned Gossip Girl; Elementary, (CBS, 2012-2019), a modern-day American adaptation of Sir Arthur Conan Doyle's Sherlock Holmes; Person of Interest (CBS, 2011-2016), which focuses on a team of vigilantes protecting innocent citizens of New York with the help of an artificial superintelligence; and Mr. Robot (USA Network, 2015-2019), depicting the revolution against capitalism led by hackers who might get more than they bargained for.

These four series were selected on the basis of two characteristics: they all deal with the digital world and go beyond our day-to-day use of communications technologies to examine and criticize the impact of the digital upon the physical, 'real', 'analog' world; despite exploring the vast cyberspace, all four are also set in New York City and make the megalopolis an integral part of their formula and long-term storytelling. One of the largest and most populated cities in the world, one of the crucibles of the United States cultural and economic power, New York is the city where everyone can succeed - or fail -, and where neoliberalism has a dramatic impact on the social and urban landscape. New York is a "global city", a part of a "global network of strategic sites"': according to Saskia Sassen, the global "re-scaling" starting in the 1980's "as a result of privatization, deregulation, the opening up of national economies to foreign firms, and the growing participation of national economic actors in global markets ${ }^{5}$ " allowed global cities to rise up as territories centralizing "complex and strategic [...] functions" for large, international firms; as a result, headquarters in these cities outsource some of these functions to "specialized service firms" agglomerating "talent and expertise" in global cities, thus creating "an extremely intense and dense information center" 6 . Beyond the private sector, three of our four television series also focus on the concentration of governmental intelligence agencies, turning New York City into one strategic node in a global network focused on both economic power and national security.

Since the city becomes global in every sense of the word, its cosmopolitanism has few equivalents across the USA, especially when combined with its worldwide economic power; multiple communities coexist in the densest American city (26,403 people per square mile), and it has become one of the most iconic cities of the western world. What is interesting about the four series we selected is that none of them could have been set in any other city: Mr. Robot sets Elliot in the heart of the economic system he is fighting against, like a virus in a computer; Gossip Girl feeds on the wealth and prestige of the city; Elementary needs an American equivalent to London; and Person of Interest is couched in the trauma of 9/11, which prompted billionaire Harold Finch to build the Machine that drives the plot in the first place. The miniature world of New York City is at the core of each of those narratives.

7 As we shall see, two main strands quickly emerge from the constant renegotiation of the binary structure of those digital/analog worlds: one deals with the (im)possible reconfiguration of power structures in the 21st century; the other, with the moral and 
legal aspects of mass surveillance. How do you manage your private life and your place in society when you're a character living in New York City, a cosmopolitan and iconic megalopolis, in the 21st century? Rather than concrete, definitive answers, what we propose here is a discussion open to further inquiry.

\section{1/ Narrative configurations}

Before we explore the cultural and political impact of the representation of physical and digital spaces in each series, we need to lay down more basic and fundamental information about these narratives. We'll break them down into two categories, following the classic narratological distinction between fabula and syuzhet, or as Gérard Genette coined it in French, histoire and récit: what happens in the storyworld and the text describing these events ${ }^{7}$. In order to do this, we'll foray into possible worlds theory applied to fiction as well as research on serialized television series. While Lubomír Doležel is our main reference in this section, we use the term 'storyworld' to put the emphasis on the fact that "interpreters attempt to reconstruct not just what happened [...] but also the surrounding context or environment embedding existents, their attributes, and the actions and events in which they are more or less centrally involved". Such context, in our case, will be heavily influenced by what audiences already know about New York City; such knowledge, whether collected from the real world or the various, numerous representations of the iconic city in fiction, generates an encyclopedia that will help the viewer fill in the gaps, gather implicit data about the storyworld", and help her make a prognosis about "the kind of world [she] should be expecting ${ }^{10 "}$. When it comes to global cities, such knowledge is further reinforced by their "general picture" ("image générale"), the global representations of each of those cities, linked to their economic power ${ }^{11}$.

\subsection{Episodic and serialized storyworlds}

9 Starting with the upper level of récit, it is worth noting that the four television series we're analyzing were all produced in North America after 2005, in an era characterized by its narrative complexity, which "redefines episodic forms under the influence of serial narration ${ }^{12}$ ". As a matter of fact, each series represents a specific blend of episodic and serialized narration, which in turn has an impact on how they depict their storyworld.

Elementary is a contemporary procedural at its core, presenting a 'case-of-the-week' in each episode while building long-term narrative threads mainly focused on the private lives of Sherlock Holmes and Joan Watson, or on ongoing investigations such as the mystery surrounding Moriarty in season one. Its use of social media, communications technologies and mass surveillance is usually restricted to the plot of a given episode, although the hacker group Everyone - a fictional equivalent to Anonymous - is a recurrent frenemy of the duo. The series treats the digital space as a common layer of investigation in contemporary police work (scanning social media profiles, secret email accounts, ...); as we'll see later, Elementary does not, however, consider it as just a mere backdrop to its contemporary adaptation of Sir Arthur Conan Doyle's novels and short stories. 
11 blogger Gossip Girl is what could be considered a macro-question which may lead to "narrative closure ${ }^{13}$ " if answered; identifying them, however, is a long-term goal that the characters sometimes leave aside, preoccupied by other family matters and romances - for example, during season three. Nonetheless, this series - the oldest of the four - systematically uses smartphones, amateur surveillance (video cameras are already a common feature of these devices), and hooks onto the rise of social media. In the teen series, characters are always faced with potentially life-altering secrets mediated through the digital space, making it a fundamental narrative device.

Person of Interest, during its first seasons, seems to be a standard action/investigation procedural using the digital space as a means rather than an end, with the Machine mentioned earlier being a mysterious black box directing the protagonists towards people in need of help. However, the artificial superintelligence (ASI) is also the narrator of the show, mediating establishing shots through surveillance cameras and generating the flashbacks of the vast majority of episodes by scanning its archives. As the series progresses, it also becomes heavily serialized, focused on the protagonists' fight against Decima, a corporation trying to engineer a ASI of its own, Samaritan; the abstract and digital fight between Samaritan and the Machine leaves the protagonists almost powerless in the physical world, while the series foregrounds its warnings against mass surveillance and questions the morality of similar (albeit less powerful), real-world programs like PRISM. focus on Elliot and fsociety's efforts to bring down the nefarious conglomerate E. Corp. A troubling take on cyberpunk, Mr. Robot is also influenced by Fight Club (David Fincher, 1999). Beyond its anti-capitalist overtones, the series borrows the idea of a main character, narrator of its own story, suffering from delusions and paranoia, leading him to believe he is enrolled into an anti-establishment hacker group while he is, in fact, the leader of that group. This in turns makes its use of digital space all the more fascinating, since it could be seen as a metaphor of the divide between Elliot and his alter-ego Mr. Robot; the blurring of every narrative limits - from the exact nature of events seen on screen to the main character regularly breaking the fourth wall and addressing the audience, or even the substitution of "E. Corp" by "Evil Corp" in all dialogues and texts - is echoed in the way the digital and the physical world are blended.

\subsection{Dyadic and hybrid storyworlds}

This brings us to the second level of our exploration: that of histoire, the fabula. Mr. Robot is almost Kafkaesque in that it uses a storyworld where, if we are to follow Lubomír Doležel's reasoning, the dyadic structure clearly separating the natural and the supernatural in classic myths gives way to a hybrid structure in which hierarchies between entities lose their meaning ${ }^{14}$. Are E. Corp's 'powers that be' only in Elliot's imagination? Certainly not, but the way they are represented is strongly influenced by Elliot's own perception - for example, when the audience realizes the opening shot of the pilot episode is actually seen from Elliot's point of view at the end of the episode, with the business men out of focus and the Manhattan skyline in the background.

TV/Series, 18 | 2020 
[Fig. 1 et 2] Opening and closing shots of Mr. Robot S01E01: in the shadows or blurred, the powerful men are unidentifiable; but the skyline, a symbol of economic power, is sharp and recognizable.
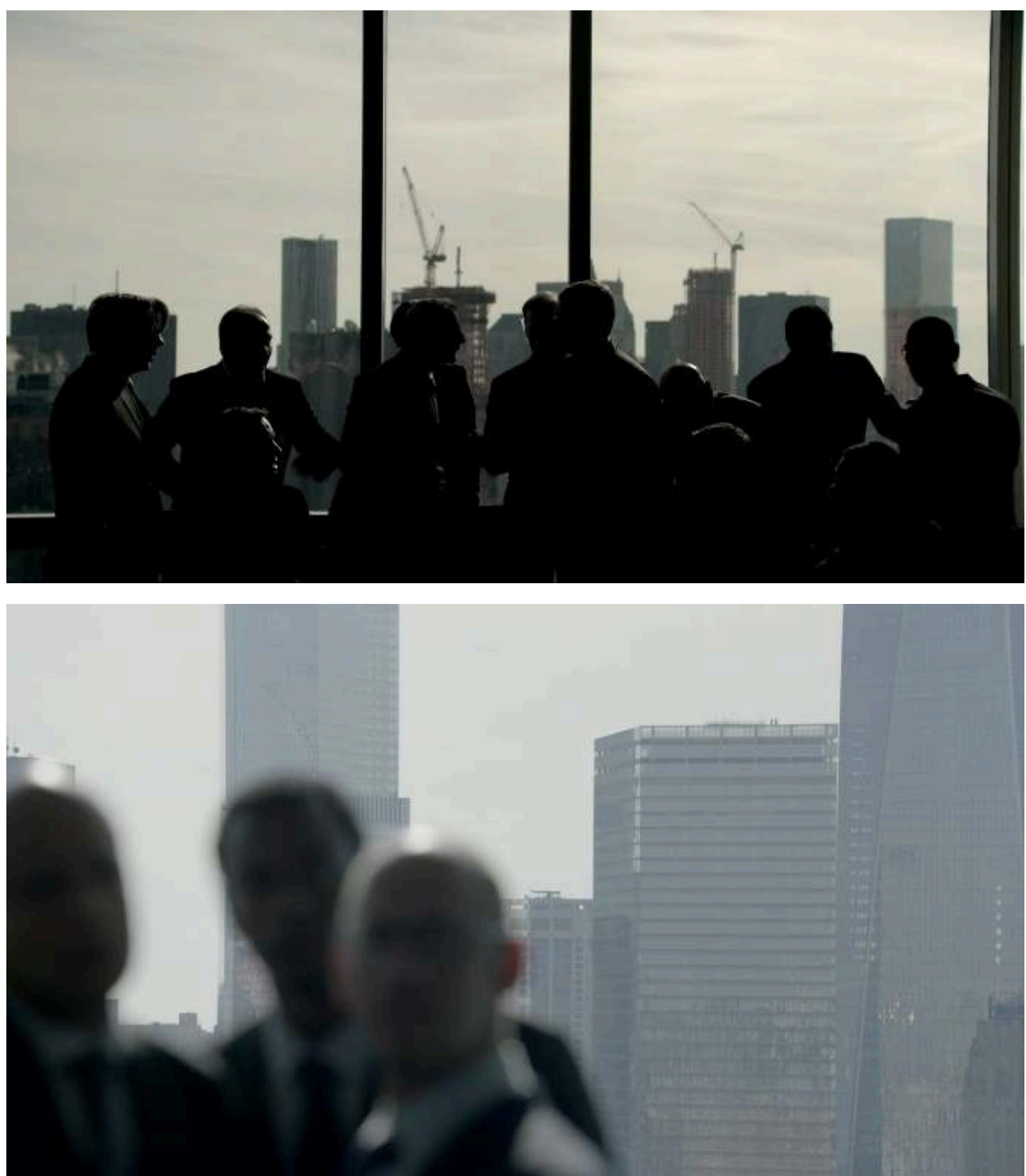

Everything is blurred in the series: every character is hacked (by Elliot, but also the Chinese Dark Army for example), everything is contaminated by doubt (from the audience) and paranoia (from Elliot), and the system against which he is fighting (the operating, electronic, digital one as well as the social and political one) is everywhere, in everything we buy, vote for, and give our attention to. Elliot's musings on his therapist's life, based on educated guesses from her clothes, jewelry, and the contents of her bag in S01E01, is the first in a long line of comments on our imprisonment in a world we think we control when we actually are at the mercy of a capitalistic and consumerist system:

ELLIOT (VOICEOVER). The world itself's just one big hoax. Spamming each other with our burning commentary of bullshit masquerading as insight. Our social media faking as intimacy. Or is it that we voted for this? Not with our rigged elections, but with our things. Our property. Our money. I'm not saying anything new. We all know why we do this. Not because Hunger Games books makes us happy. But because we wanna be sedated. Because it's painful not to pretend. Because we're cowards. ELLIOT (OUT LOUD, IN A SHOT HAPPENING IN HIS IMAGINATION). Fuck society. 
In Mr. Robot, the narrative endgame seems almost impossible to attain as the corruption of our world by capitalism combines with Elliot's inescapable doubts about his identity. There are no digital and physical spaces: there is only one blurred and confusing space running on a corrupted operating system.

We want to insist on the importance of storyworld structure, as Person of Interest, which is also associated mainly with science fiction, displays a more classical, dyadic structure (in Doležel's terms) in its later seasons, with the ASIs being deemed "gods" by Decima's CEO at the conclusion of "Deus Ex Machina" (S03E23), while quoting Shakespeare:

GREER. What a piece of work is your machine, Harold. "In action, how like an angel. In apprehension, how like a god." In 20 years' time, life on Earth will come to resemble the myths of the ancient Greeks. A pantheon of super intelligent beings will watch over us, using human agents to meddle in our affairs. Or they may simply destroy us all. One could argue we've done a fair job of that ourselves.

Person of Interest then goes beyond our contemporary world and tries to imagine one where the digital space becomes an unfathomable domain where ASIs fight for dominance, while the physical world, redesigned with restricted accesses to the digital world, is only ever a subordinate, at the whim of its masters. The balance of power slowly switches from the physical, 'real world', to the cyberspace, as 'analog' superpowers are rendered useless by the very system (in the technological sense) that they designed to preserve the system (in the economic and political sense). The threat, here, is the replacement of humanity by artificial intelligence at the top of the pyramid of power. The interventions of the Machine and Samaritan through their avatars (humans equipped with earpieces), for example in "The Cold War" (S04E10), foregrounds this interpretation of the digital world as a realm slowly escaping the grasp of human beings and becoming a divine 'top layer' of reality. Person of Interest is increasingly filled with 3D visualizations of this cyberspace over the seasons, while the ASIs fight to escape the physical world. The location of the Machine, first in a government facility, then redistributed all over the United States, hidden in power relays, is a major plot thread in season four, before Samaritan destroys it and its core code ends up in a single briefcase; rebuilding the system from scratch is the main goal of the protagonists during season five, with the physicality of the Machine (installed on a network of 300 PlayStation 3s) denoting its extreme vulnerability: to get to the digital world and fight Samaritan, it must first be upgraded in a secure, isolated space, before being powerful enough to ascend into 'the heavens', in a satellite, in the series finale, finally becoming the God hacker Root predicted it would be as early as season two.

Meanwhile, belonging to more "empiric ${ }^{15}$ " genres such as the police procedural and the teen drama, Elementary and Gossip Girl treat the digital world as a sub-layer of the physical world, albeit a powerful one. Of the two, Elementary is perhaps less focused on cyberspace, even when it uses it more systematically than Gossip Girl. The 'real' world, with a focus on the professional relationships between the protagonists coming from various communities, and the weight of hard, physical evidence during investigations, is where Elementary deploys its narrative strategy, especially since the American city of New York is one of its 'unique selling points' against the British series Sherlock (2010-2017), moving the eponymous character in contemporary London. For Elementary, New York City, as a cosmopolitan city with a rich history and a diverse population, is the perfect setting for a wide array of possible plots and their associated shooting locations (lavish offices, poor neighborhoods, docks, museums, high-tech startups, 
suburban residential areas, parks, universities ...); thus the city is mostly presented as a mosaic and not a unified space, with varied settings usually characterizing the 'suspects of the week' and helping the writers to set, act after act, the confrontation between social classes that the series usually explores. Elementary focuses on the rising "spatial and socio-economic inequality" that Sassen considers to be one key characteristic of global cities ${ }^{16}$. For example, frequently running into the rich and powerful during their investigations, Holmes and Watson generally meet them in their offices, in scenes using New York City's skyline to denote their social ascension.

Gossip Girl may seem less interested in lower-class characters. During its first seasons, it plays with the opposition between the luxurious Upper East Side and the cozy lofts of Brooklyn. It foregrounds the reformulation of power moves and twisted relationships in the upper-class dynasties of the 21st century, where a single photo can be instantaneously uploaded to a blog, or a sextape may destroy a reputation. While a series like Gossip Girl is focused on what can be seen - especially during the advent of smartphones video cameras - neither voice-overs nor shots make it clear how most of the day-to-day stories end up on the blog - until the series finale outs Dan Humphrey as the titular blogger.

[Fig. 3 and 4] Shots from S01E01 and S01E10 of Gossip Girl: 'Mel' and Chuck Bass sending tips to Gossip Girl, either for gossip or outright vengeance.
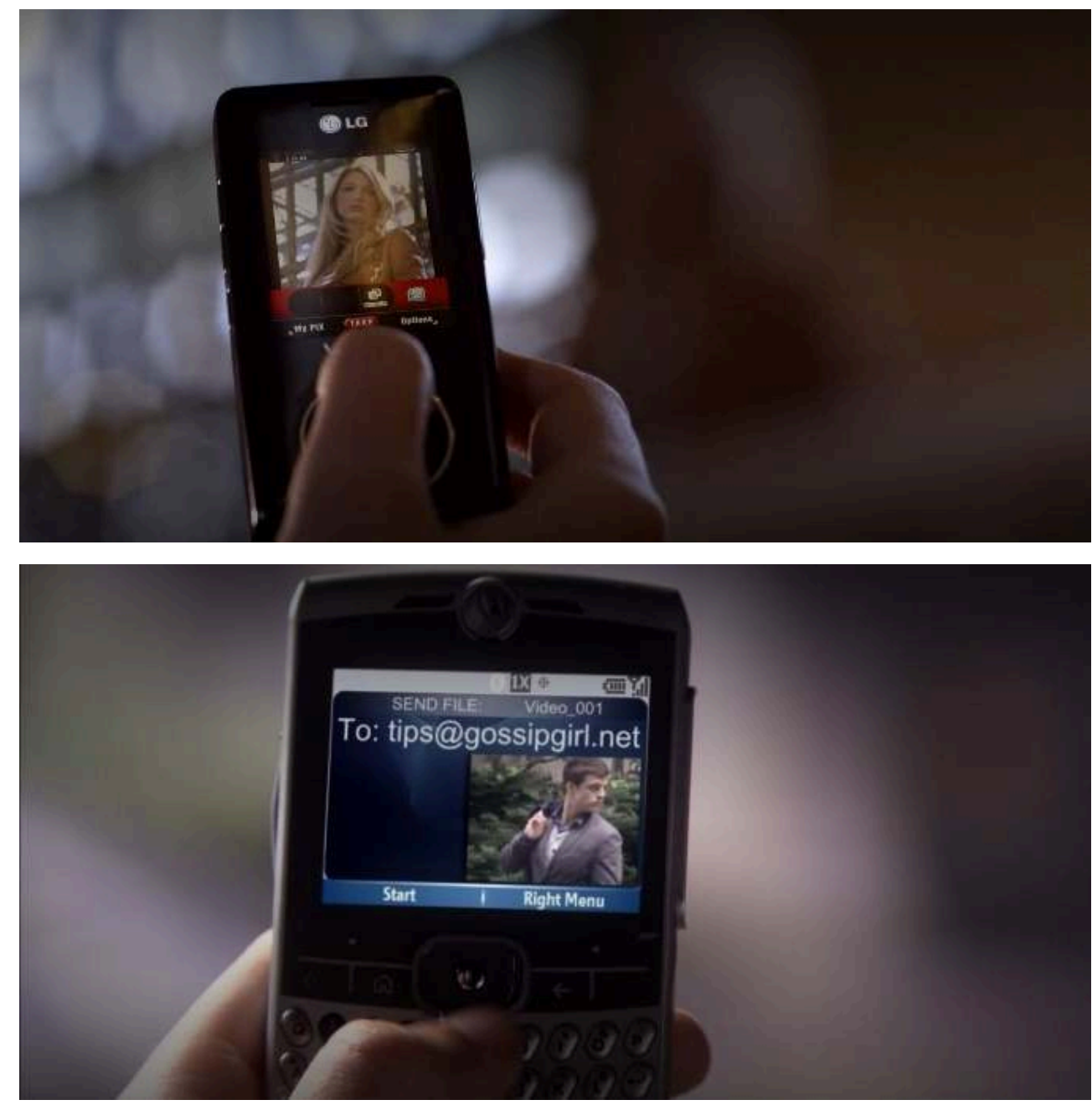
21 Each episode, especially in the first seasons, may feature a character taking a photo or sending a text to Gossip Girl, but mostly, it seems like the audience is both the witness and informer, and Gossip Girl an omniscient and elusive homodiegetic narrator hidden in the digital sub-layer of reality. Their voice-over narration is especially interesting since it is a woman's voice (in this case, actress Kristen Bell), giving her a privileged status few female narrators currently have on American television ${ }^{17}$, reminiscent of Carrie Bradshaw's columns in Sex and the City (HBO, 1998-2004), also set in the Big Apple.

22 Now that these basic and descriptive - but nonetheless important - characteristics are laid out, we now would like to divide them along two major thematic strands we isolated in the representation of the confrontation between physical and digital space in New York City, starting with the matter of mass surveillance.

\section{2/ Hiding in plain sight: mass surveillance in Elementary and Person of Interest}

23 Years after Edward Snowden leaked top secret documents detailing the NSA mass surveillance of U.S. citizens, after Facebook came under fire for gathering and sharing much more information about its users than advertised, and after countless other debates and scandals about surveillance cameras, facial recognition, and online security, the general public is now more than ever aware that our digital lives, as well as our every move in the physical world, are recorded and archived and can be used against us. Like any megalopolis, New York is indeed at the heart of those controversies, especially since one of its most curious and well-known landmarks is a 29 floor, windowless brutalist building built in the 1970s and supposedly owned by telecommunications company AT\&T, that may have "served as an NSA surveillance site", according to an investigation led by The Intercept, based on documents obtained from Edward Snowden ${ }^{18}$. The 'Long Lines Building' has indeed become, in season three of Mr. Robot, the site where E. Corp gathers its analog archives to try to rebuild the database fsociety deleted. The dense surveillance network of the city is another matter of concern for police procedural as well as science-fiction television series, as this year, another major American city, San Francisco, issued a ban on facial recognition technology ${ }^{19}$.

24 In this section, we will mainly focus on Elementary and Person of Interest, as they are more directly concerned with matters of privacy and mass surveillance, and offer two different points of view, opposing consultants for the NYPD for the former, and a team of vigilantes for the latter.

\subsection{Elementary}

Like most contemporary police procedurals, Elementary relies heavily on mass surveillance and takes convenient shortcuts through surveillance cameras and e-mails to quickly get around red herrings and pursue more complex leads as each episode unfolds. Both Sherlock and Joan, along with Detective Marcus Bell, frequently check their smartphones when investigating, reviewing material gathered by the police or looking at news feeds. When it comes to that specific device, the series is in a bit of a mise-en-scène cul-de-sac, as the British television series Sherlock already broke new 
grounds by using a sleek, minimalist approach to the representation of texting conversations and web browsing as text floating in the shot, without having to actually cut to an insert of the phone. Elementary then does the opposite: it shows inserts of smartphones and computer screens in a realistic and conventional way, but compensates by having Sherlock and Joan usually print all documents related to an investigation and create an analog crime board, similar to those usually found in police precincts, except theirs are assembled over the library fireplace or in the study, in their cozy brownstone.

This brings us to the more discrete, but equally engaging way Elementary adapts the character of Sherlock Holmes for the 21st century. At least a third of each episode will usually take place inside the brownstone, both a domestic space and workspace for the duo of police consultants. Rather than being the machine-like being Benedict Cumberbatch plays in the British series, Jonny Lee Miller gives life to a more down-toearth detective, aware that he must constantly train and learn: Sherlock - and Joan, as she picks up the tricks of the trade - constantly experiment, whether it's lockpicking, training the olfactive sense, building models, or... practicing trepanation (S02E14). At the same time, beyond those analog, homegrown hobbies, the duo is well acquainted with technology; above the study and its analog crime board, the "media room" is filled with screens upon which Sherlock is used to monitor many different feeds at the same time - either news stations or surveillance videos, acting like a security agent. Those screens also echo the use of New York City as a geographic, social and cultural mosaic. In a way, they bring the entirety of New York into the brownstone through various analog and digital spatial representations in order to solve crimes.

[Fig. 5 and 6] The brownstone in Elementary can also be described as an analog and digital mind map, blending the entirety of New York and the thought processes of the detective duo within a compartmentalized space.

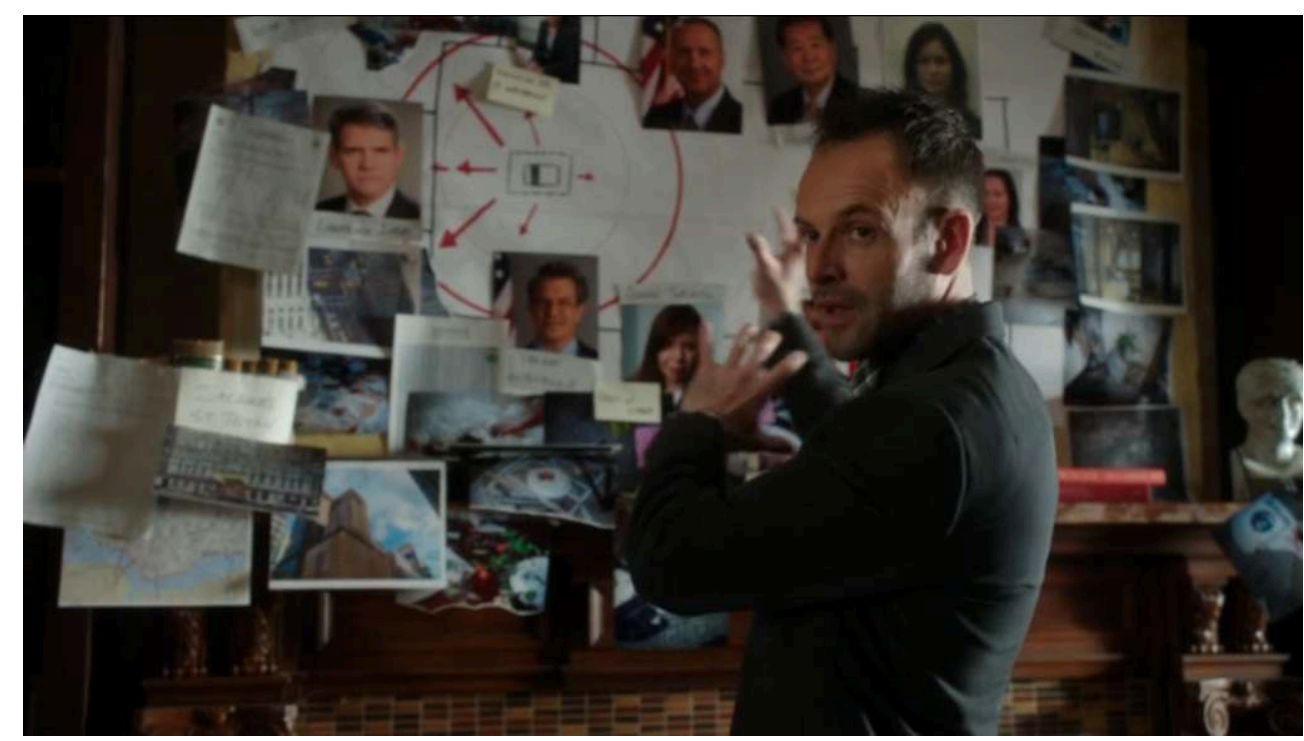




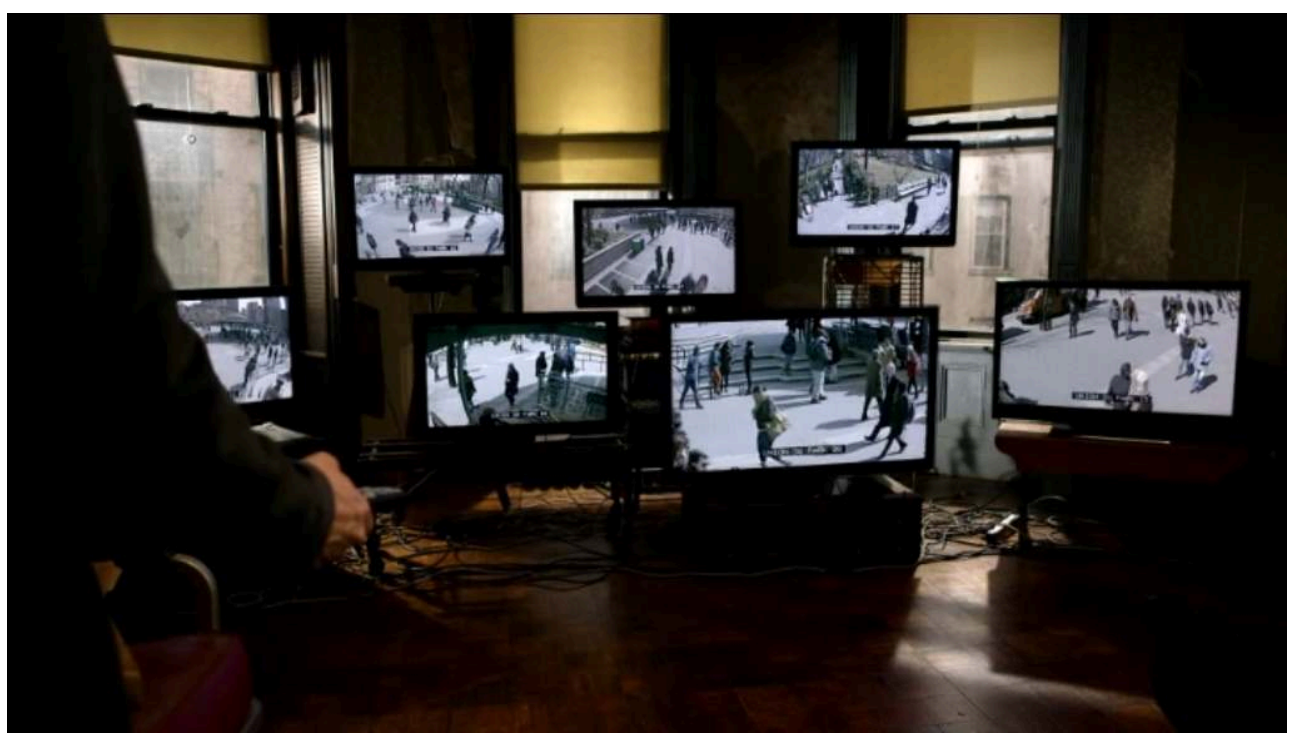

Beyond that blend of analog and digital means of investigation, the series also draws a very blurry line between the documents obtained through their collaboration with the police - or various government agencies - and the ones they gathered by themselves, scrolling through social media and public archives. Elementary makes it seem like it is both completely possible and very acceptable that two civilians, consulting with the police, would have access to so much private and public data, and the means to process it better than the police, the FBI or even the NSA; the brownstone, in Elementary, is an intelligence node not unlike the 'Long Lines Building'. Still, they usually require help from the outside.

Just as Mr. Robot has fsociety, a hacker group whose only identity is a mask from an obscure movie, and Person of Interest has Vigilance during season three, Elementary has its own equivalent of real-world group Anonymous: Everyone, first appearing in "We Are Everyone" (S02E03). Never seen onscreen beyond rare peeks at Sherlock and Joan's computer screens, they are closer to what the general public experiences in the real world with Anonymous. Invisible, dispersed, with no apparent leader, and spending their time on darknet forums and chatrooms. In a way, they end up being the modernday equivalent to the original Sherlock Holmes "irregulars" informers, even if this incarnation of Sherlock still has "irregulars" that he meets in the flesh, through Skype, or both (for example, mathematician Harlan Emple). But contrary to the other, clearly identified irregulars, Everyone acts less as a positive force of resistance and more as a group of very bright people who like to play games. For every tip Sherlock asks of them, he is forced to perform a task; this becomes a running gag over the course of the series (for example, being hit by random passersby and singing a song from the movie Frozen in S02E19).

Everyone becomes a convenient plot shortcut of unimaginable power, for example when the duo tracks down the administrator of a darknet website (S06E12) with their help; all the audience sees are Sherlock and Joan meeting with the suspect in a bar, telling him: "We know people who are good with computers. They were able to unmask you as the site's administrator and ping your location." The subsequent arrest of the man by Homeland Security, tipped by Sherlock himself, is troubling: even when the crime is proven true (the suspect was indeed running a site where members of the InCel community discussed murders and acts of terror against women), the fact that 
two 'consulting detectives' could identify and locate someone faster than Homeland Security in a city of more than eight million inhabitants is never treated as more than a demonstration of the power of Sherlock's network. The irony being (especially in one of the seasons most focused on plots involving the use of internet), that the detectives are shocked to learn, a few episodes later, that their home address is available on a public website listing private investigators in New York City, and they immediately ask to have it removed (S06E15).

Thus, the series never takes a clear and definitive stance of Everyone, or mass surveillance for that matter, but it takes every possible opportunity to address state surveillance, using New York City as an international hub for intelligence agencies, both foreign and domestic. Over the course of the series, the duo works occasionally with the NSA, the FBI, the DIA (season five), Interpol, MI6 and even the Mossad (in S02E18). These agencies usually hide in New York City, and the protagonists sometimes stumble upon them by accident: during season two, when the series broadens its horizons, they first meet NSA agent McNally in a so-called web-development company (S02E13) before encountering the Mossad in a fake travel agency (S02E18). Sherlock usually demonstrates his intelligence by instantly suspecting something is amiss and proving less than humble in front of these government intelligence agencies, for example to agent McNally in S02E13, after noticing PRISM identification numbers on phone records they obtained from a mob boss ("suffice it to say that yours is one of several NSA fronts that I have identified in the last 18 months").

In Elementary, New York, a megalopolis with worldwide power, is full of spies and closely watched by intelligence agencies, and no secret, online or offline, can escape the grasp of Sherlock and Joan; their methods echo those of hackers as, even if they don't actually hack websites and infrastructures, they still use internet, surveillance footage and social media to crack each case while brainstorming and leading experiments in their brownstone. In a way, what makes the series unique could be that its protagonists modus operandi is somewhere between contemporary hacker culture (digital) and DIY culture (analog) ${ }^{20}$. While they don't delve into robotics and the likes, Sherlock and Joan could be seen as detectives influenced by the maker culture, with the brownstone as a fab lab of sorts, where they offer their craft and expertise to the police and citizens of New York City.

\subsection{Person of Interest}

Broadcast between 2011 and 2016, Person of Interest makes it clear that both its plot and its setting are directly related to the $9 / 11$ attacks during its pilot episode, in which Harold Finch, billionaire philanthropist, hires ex-CIA agent John Reese to help him investigate the social security "numbers" the Machine he created sends him, indicating that these people are either a future victim or perpetrator. These "numbers" are considered "irrelevant" by the U.S. government who only uses the Machine to detect major "acts of terror", leaving Finch no choice but to create a 'backdoor' into its own system. Reese, being a pragmatic henchman at the start of the series, asks the obvious question:

REESE. So where is the machine now?

FINCH. What, the drives? Who knows? A government facility somewhere. But the machine? The machine is everywhere. Watching us with 10,000 eyes. Listening with a million ears. 
If it may seem more 'science fictional' than Mr. Robot, Person of Interest is no less prescient in that, by addressing U.S. mass surveillance on its citizens two years before the PRISM scandal (which is referenced in season three as a 'decoy' hiding other, more powerful programs such as the Machine), the series was at the front row of the debate on state and corporate surveillance in an era where everyone is equipped with their own cameras and microphones, and the public spaces of every American city are even more heavily monitored following $09 / 11$. New York City is the perfect place to lead this debate in a work of fiction.

Contrary to a common saying, a city cannot be a 'character' (in the narratological sense) in a work of fiction, unless it has "a mental life and reacts emotionally to the states of the world ${ }^{21 "}$; that being said, the Machine itself is slowly becoming a character in its own right over the course of the series, showing signs of emotional attachment to its creator, Finch, and to the rest of the protagonists ${ }^{22}$. And that character is defined by sense organs, microphones, cameras, that we primarily see in action in New York City and its vicinity: each act, each scene is usually introduced by statics (as thousands of people are being monitored in a single area) and at least one shot from a surveillance camera. In this sense, the Machine could be seen as embodying the city of New York: its physical appearance, with recognizable landmarks and graphically coded information such as its restricted airspace; as well as its economic and political power, fighting against Samaritan when it disrupts Wall Street (S04E10), helping the protagonists dismantle a network of corrupted cops going high into the NYPD hierarchy, or solving political dilemmas when serving both the U.S. government and the team of vigilantes the former is tracking.

The Machine constant monitoring of public and private spaces is defined by the series as a morally ambiguous situation, all the more because, this being a science fiction television series, it questions the very definition of morality when applied to an ASI, for example in S04E05, where Finch is convinced the machine will quickly "replace" them if they die, while hacker Root is convinced it "cares" about the team. The Machine is not there to judge, and leaves it for humans to decide whether the number-of-the-week is a good or bad person; but its constant monitoring of U.S. citizens is presented as something illegal from the start, a metaphor for the systems already in place in the real world.

The protagonists thus have to hide from the government: their headquarters, first an abandoned library, then a derelict subway station, contrast with the control rooms of Decima, similar in design to workspaces both in private companies (numerous desks aligned in front of team managers) and intelligence agencies (for example, as seen in another Bad Robot production, Alias, ABC, 2001-2006). Furthermore, when Samaritan, the evil twin of the Machine, is activated, the protagonists are forced to rely on a "shadow map" ("Prophets", S04E05), showing the rare surveillance-free zones in the city of New York. During most of season four, they need to "hide in plain sight", as Samaritan is tracking them, unaware that they hacked it just in time to change their identities and give him a minor, but vital, "blindspot". New York City, once defined as the 'body' of the Machine, becomes an estranged space invaded by another 'mind', Samaritan; while the city is not a character, it goes through what Jason Mittell calls a "character overhaul": a complete rewriting of the identity of a character still played by the same actor or actress ${ }^{23}$. New York City is fractured, a space both trustworthy and untrustworthy, depending on which ASI is spying on the protagonists. 
Being vigilantes, they always hide in the shadows, spy from afar, before quickly intervening and fleeing the scene; the fear of being monitored by Samaritan forces them to control their appearance in public in season four, as the places they go to and the people they interact with must not stray far from their cover identities, echoing real-world issues in global, dynamic cities where body movements and trajectories are a product of neoliberalism urban design, and stillness becomes suspect and can even identify one as an "enemy" of capitalism ${ }^{24}$. The effect is jarring as the protagonists must "play" their alternate, cover identities not only with words and actions but through the way they use and navigate their environment, key characteristics of a television series character ${ }^{25}$ : the beginning of season four thus forces the city-Machine system and the protagonists to undergo an overhaul, luckily incomplete and reversible, but clearly determined by environmental pressure upon the characters, as identity and space are interlocked.

As we discussed, Person of Interest sets the digital world as a top layer of reality, a divine realm; this is made clear through the use of 'God Mode', a term derived from video games where the player is granted god-like powers. The Machine or Samaritan may choose to use "analog interfaces", humans, and direct them with uncanny precision as they see everything: as soon as "God Mode" (S02E22), Reese answers a call from the Machine, which uses recorded voices to direct him, with instructions such as "four o'clock"; when he loses his earpiece, the Machine successfully faxes Reese the detailed weaknesses of the opponents that have captured him, with one of them reading the list aloud without realizing what it is before it's too late (S04E22). As the series slowly adopts Samaritan interface for establishing shots and flashbacks, its own analog interfaces can be seen shooting through walls, hitting targets no human ever could, while shots from surveillance cameras help the audience see how both ASI are reacting and countering the attacks of the other.

[Fig. 7 and 8]: in S04E05, Root, interfacing with the Machine, and Martine Rousseau, with Samaritan, shoot at each other without even seeing each other. they are tools in the hands of artificial intelligences.

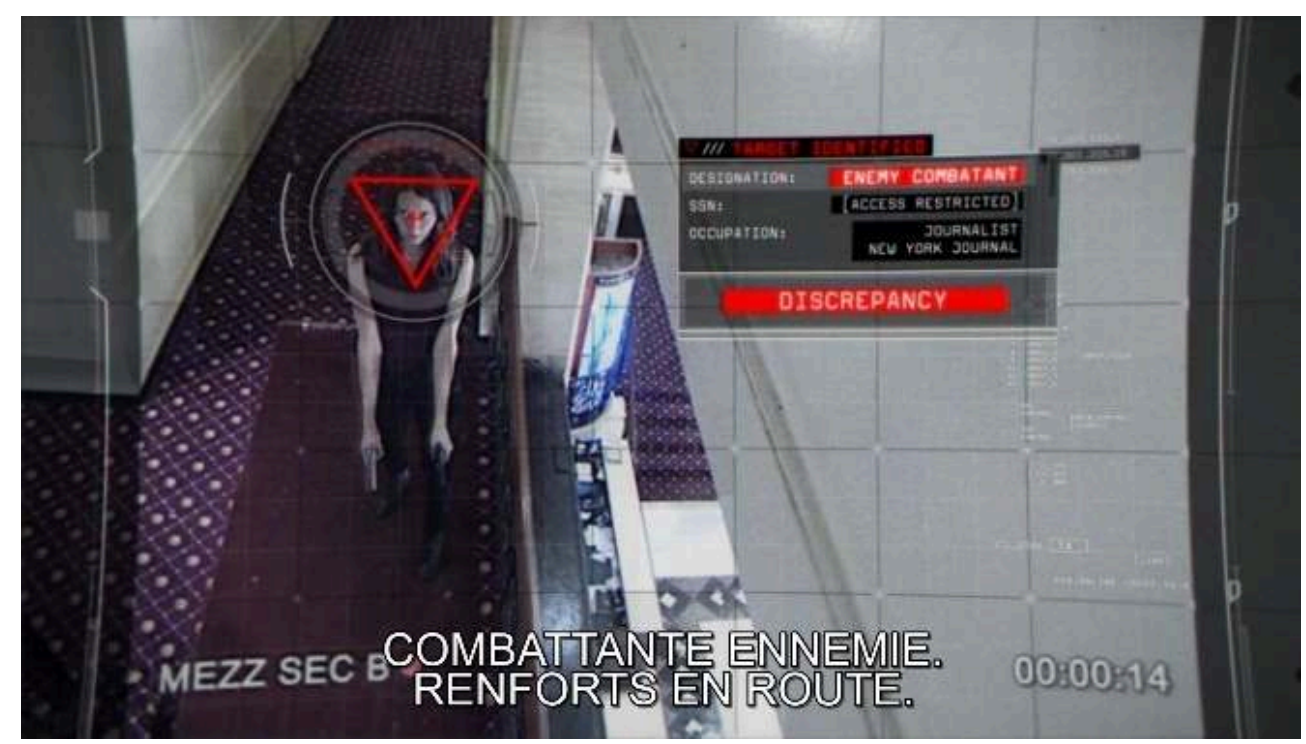




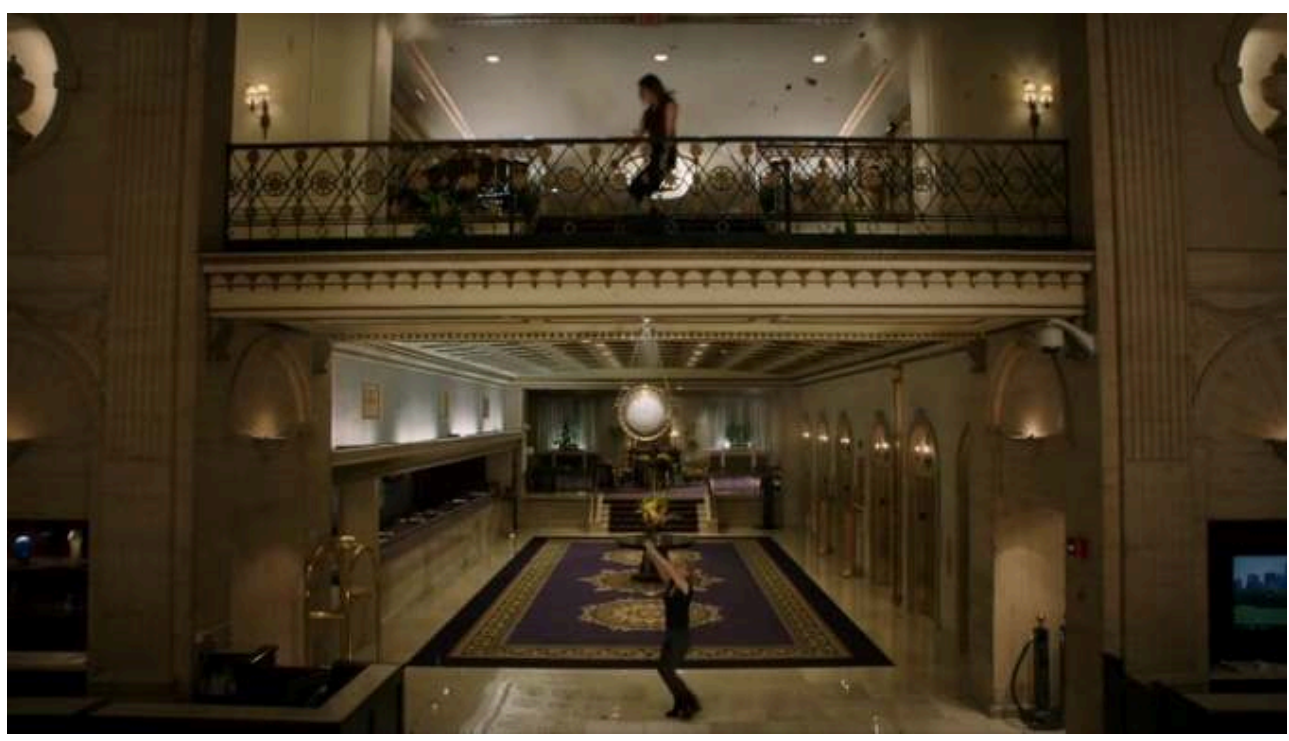

Person of Interest has no intentions of openly criticizing the U.S. government, but it is indeed more wary of mass surveillance than Elementary and questions the need for a surveillance network as powerful as the one built in New York City; a network that can easily become a weapon when the wrong bills are passed in Congress, and when companies and governments choose security over liberties. The fact that Samaritan slowly becomes the narrator of the series, whose eyes oversee everything and tag the protagonists as "enemy combatants" in the city that embodies the trauma of the century in the American psyche, is typical of works of science fiction that can only criticize the society that created them so far as that society allows them to ${ }^{26}$. In the series finale, the 'good' God prevails, watching over the world, still warning the government of possible acts of terror, and the surviving protagonists of possible crimes; but it can do so as a free agent, loyal to no one, protecting everyone, because humans cannot be trusted with such power.

\section{3/ The powerful and the powerless: Gossip Girl and Mr. Robot}

While every television series set in one location may, over time, make it feel like said location is connected to the rest of the world with characters coming and going, New York, as a cosmopolitan megacity, offers the perfect setting for the most powerful and the most powerless to meet. Minimal exposition is required to understand where power lies in New-York: the Upper East Side displays lavish buildings and world-class museums, while the Financial District harbors the World Trade Center and Wall Street, landmarks shaped by, and shaping, increasing social inequality in the global city. However, when it comes to the digital space, nodes of power are more elusive and difficult to pinpoint, thus creating narrative tension. In this section, we will mainly focus on Gossip Girl and Mr. Robot as they are more specifically concerned with power relations and offer two distinct point of views: that of the powerful and powerless, respectively. 


\subsection{Gossip Girl}

41 settings. The luxurious apartments, acting as domestic spaces, help characterize the protagonists, especially their tastes and their wealth. The 'poorest' protagonists are already high up on the social ladder: the Humphreys live in a cozy loft in Brooklyn, denoting their bourgeois 'boheme' culture, with the father, Rufus, a musician who owns an art gallery, and the children, Dan, an aspiring writer, and Jenny, future fashion designer, being considered as social climbers, located somewhere between middle and upper class. Later, following Lilly and Rufus' wedding in season three, they move to the Upper East Side with the Van der Woodsen. It's interesting to note that in the original book series, the Humphreys live in the Upper West Side, denoting 'new money', whereas the television makes their social ascension all the more explicit, especially when Dan is revealed to be Gossip Girl in the series finale: what they lack in money, they make up for with information, thanks to Dan.

Thus the entire television series revolves around the Upper East Side, and when the characters move to public spaces, they again end up in fancy clubs, prestigious art galleries or theaters, political rallies, where they are usually photographed by paparazzi (especially starting with season three) and, as socialites, used to control their behavior, their appearance, to present themselves as their best possible selves. Which, in turn, offers the main narrative drive of the series: none of the protagonist can hide who they really are, and if they don't slip themselves, Gossip Girl will always be there. It is all the more ironic that this gossip war, tearing apart the old-school aristocracy of the Upper East Side, is fueled by a social climber from Brooklyn who, in the end, is accepted into the world he criticized. Gossip Girl never had any real intention of threatening the system.

Another recurring setting for the series are private schools and colleges, since the main protagonists are young adults. These are perhaps the spaces which present the most clearly defined hierarchies, especially Constance Billard School for Girls, where Blair Waldorf fights for the title of "queen", followed during season three by Jenny Humphrey. The unofficial title of "queen" of Constance, a perfect match for a protagonist so attached to the old values of aristocracy such as Blair, is explicitly linked to a war on information, with the crown being won by whoever brings the juiciest piece of gossip to Nate's party in "The Goodbye Gossip Girl" (S02E25). Ironically, hellbent on ending the monarchy at Constance, Jenny becomes what she fought against during season three, after she learns critical information from a secondary character, Jonathan, who hacked Gossip Girl's server in S02E25.

This episode is also the first time that the audience gets a peek at the 'real' queen of Constance - and the first time the protagonists actively try to uncover their identity. Eric and Jenny discover a long list of tips, such as the ones protagonists and secondary characters send to Gossip Girl via text messaging; except they are left to guess why they doesn't use them all, perhaps waiting for the perfect timing. After the blogger blasts out everyone's dirty secrets during graduation, they inform the protagonists that they will follow them to college, despite their hope that Gossip Girl would continue to target high-school students. Sending them a text claiming that everyone who ever sent them a tip could be considered 'Gossip Girl', the blogger nonetheless proves that their ubiquitous, digital aura is bound to one physical being, a student graduating with them.

TV/Series, 18 | 2020 
Jenny's fall to the dark side during the third season, while she's still at Constance because she's younger, could be seen as a collateral damage of Gossip Girl's move from high school to the prestigious colleges of New York City: outside of her bubble of influence, not only tied to a specific space (the Upper East Side ${ }^{27}$ ) but also a specific generation, the power struggle becomes vain and defined not by information, but by bribery (the Yves Saint-Laurent handbags Jenny gives to her minions in S03E12) and drug dealing ${ }^{28}$.

Interestingly, Gossip Girl's identity becomes a major plot thread again during season five, in which the protagonists learn that with great (digital) power comes great responsibility: after a car accident which almost kills Chuck and Blair, the real Gossip Girl abandons the website (S05E10), only for it to be picked up by the protagonists' frenemy Georgina; then Serena herself, who quickly endangers her friendships by running the site, before it returns to its rightful (and still anonymous) owner. Refocusing its own digital world around one website - in fact, one role, that of administrator - Gossip Girl comes full circle: administrating the site is a role akin to that of a queen, an unofficial regent of the Upper East Side, controlling the physical world through the digital one, at the risk of destroying the former until the return of the rightful queen: Dan Humphrey, writer, social climber, anonymous truth-seeking blogger by night. In Gossip Girl, the digital mask worn by the character represents its only way of blending in the royal court of the Upper East Side: while every protagonist has secrets of their own, he owns their secrets.

\subsection{Mr. Robot}

Geographically speaking, Mr. Robot mainly operates on the sidelines of New York City, although the nexus of all power - and, explicitly, of all evil ${ }^{29}$ in this case - E. Corp, is one of the main settings of the series. While every protagonist in Gossip Girl belongs or meddles with the upper class, most protagonists in Mr. Robot are anarchists and hackers living their secret lives on the edge of society and belonging to the lower middle class; the antagonists are either E. Corp's top officers, vice-presidents, and CEO, or the members of the Chinese Dark Army led by the mysterious hacker Whiterose, a transgender woman who is also (when presenting as a man) the Chinese Minister of State Security. While the FBI does briefly visit Beijing during season two, investigating the Dark Army, New York City is the focus of the series, especially since E. Corp CEO Philip Price is collaborating with the Chinese Minister of State Security. Thus the series spends its time between two main settings.

First, a well-identified workspace, either E. Corp's building ${ }^{30}$ or the security firm Allsafe. These spaces are archetypal: grey, oppressing cubicles for the white collars, luxurious offices and conference rooms for the officers. The relation between E. Corp, an international firm, and Allsafe is precisely defined by the outsourcing of complex functions by the former, in this case cybersecurity. Allsafe is a minor node of the global conglomerate that is E. Corp.

Second, a variety of rather undefined spaces more or less denoted as domestic, whether it's Elliot's apartment, the arcade where fsociety is hiding in season one, the lavish apartment of an E. Corp officer in season two, the prison in which Elliot spends some time, etc. Neither of those offer safe haven to the protagonists for long; Elliot's apartment, the most 'domestic' space since he is able to lead, to the best of his abilities, 
a social life and a romantic life with his neighbor Shayla, is contaminated with paranoia: Elliot can be seen multiple times destroying his entire computer setup to wipe all data.

For these protagonists living on the edge, in messy, derelict or illegally occupied buildings, tracked by the very institutions and conglomerates they are trying to topple, the cyberspace appears to be both the manifestation of a liminal space and the only mean of resistance. Mr. Robot is interesting from a generic point of view because it might be, indeed, "a TV show that'll mess up this generation's idea of hacker culture", as Leslie Romero says to Mobley while they're watching an awful TV movie about cyberviruses (S01E04). Rather than trying to represent the cyberspace through any visual representation that would fall short of what it even is, the series sticks to the character's computer screens, command inputs and obscure code, all of which is designed to be the most accurate ${ }^{31}$. Since it is not a defined space, the cyberspace becomes an elusive layer of reality, akin to the lies told by governments and corporations (Elliot: "We haven't lived in anything remotely close to [reality] since the turn of the century", S01E10) or even our own senses (Elliot: "Sure, we rely on them, trust they accurately portray the real world around us, but what if the haunting truth is, they can't? That what we perceive isn't the real world at all but just our mind's best guess?", S02E12). The cyberspace is everywhere and nowhere, the source code of 21st century reality.

50 Coupled with an unreliable homodiegetic narrator frequently breaking the fourth wall, a dilated timeline (the events of the four seasons all happen over the course of 2015), and a disturbing, oppressing shot composition systematically forcing the characters to the sides or the bottom of the frame, Mr. Robot thus presents us with a fluid and complex narrative space where postmodern anguish and late capitalism give way to what appears to be, at first, an unprecedented economic crisis as fsociety wipes E. Corp's records and archives at the end of season one, and ends up looking like the end of the world, with power blackouts during season two and three. Underlining the blending of physical space and digital space, the act of wiping E. Corp's data amounts to physically destroying a part of New York City, as the global city starts to crumbles; the upper class is spared - as it was from the 2000s global recession in the real world -, but social inequality actually increases as people lose their savings. It is interesting to note that, as the series progresses, the corporate spaces of power and the liminal spaces of resistance and unrest are always separated by cuts, which appears to be a classical, logical editing choice, especially given the widening gap between the $1 \%$ and the rest of the population... until "eps3.4_runtime-error.r00" (S03E05) blends these spaces together in one long take that covers the entire episode.

51 At this point, Elliot, trying to reverse the chaos created by fsociety and the Dark Army, works at E. Corp to help them salvage their data; he is fired by his friend Angela Moss, now working for the Dark Army, and tries to stop them from destroying the 'Long Lines Building'. The camera circles around the characters, both powerful and powerless as the situation derails; elevators are used to discreetly cut between studio takes and exterior shots on location, in front of 135 East 57th Street, circling around the protesters while Darlene, Elliot's sister, confesses she works with the FBI; then the camera follows the protesters as they break into the building, before tracking Angela, still trying to hack E. Corp in order to help the Dark Army. Visually stunning, the long take follows Angela around 32:30, positioning itself above the wall of the building, 
seemingly passing through it like a ghost, and joining the server room in which Angela is operating with the exterior, high angle shot of the protesters $400 \mathrm{ft}$ below. This episode, which could be considered one of the most important turning points of the entire series, takes place during another, major event: the U.N. Security Council vote allowing the people's Republic of China to annex the Democratic Republic of the Congo, with brief peeks to a news anchor underlining the possible disturbance in the balance between "world superpowers and impoverished nations". The long take makes it seem like the revolution is finally underway, with both protesters and camera 'breaking into' E. Corp headquarters from the bottom, while nobody is paying attention to the real, counter-revolution happening on the other side of the globe, as China is moving to the next phase of its plan.

[Fig. 9 and 10] Two shots from Mr. Robot S03E05: protagonists are never in the center of the frame.
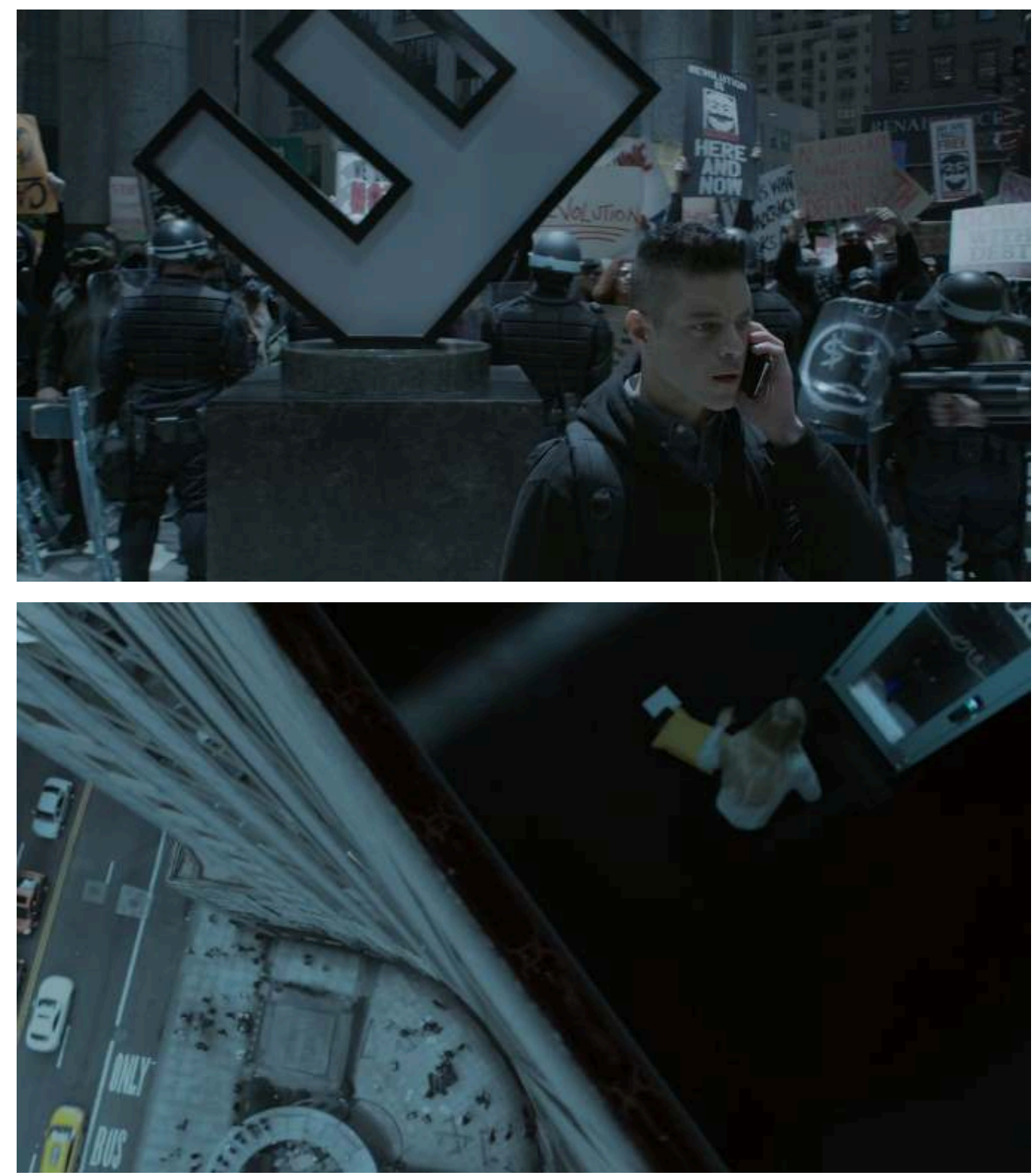

52 Even more disturbing are the following episodes, underlining the fact that Elliot and Mr. Robot's revolution was just part of Whiterose and China's endgame: threatening global economy to facilitate a move towards digital currency, and then taking control of E. Corp to lower the value of their "Ecoin", favoring China after the country adopted 
bitcoin. New York, a "strategic site" in a global economic network, then becomes the 'server' that China needed to hack in order to cripple the United States, possibly the rest of the world - just like Elliot leaves fsociety's file in one of Allsafe servers in the pilot episode, unknowingly starting this intricate, global plot. After the Dark Army attack on 71 E. Corp sites across America in S03E07, Irving, working for the Dark Army, wakes up Elliot/Mr. Robot and shows him something up in the distance: a rooftop terrace filled with rich people partying.

IRVING. You know why those people are enjoying themselves so much, even though thousands died today in the biggest attack in U.S. history? [...] See, kid, that's been your mistake the entire time, thinking this whole thing's about your silly little plan. No, your revolution was only allowed to happen 'cause it was bought and paid for by people like them. Face it, no matter how hard you try, that's always the end result.

Mr. Robot displays an evolving storyworld structure similar to that of Person of Interest: the digital world becomes the top layer of reality, as conventional methods of action and government agencies are rendered powerless. But where Person of Interest makes that top layer the domain of artificial gods, recreating the dyadic structure of ancient myths, Mr. Robot insists on showing cyberspace not only as very porous, but also controlled by humans - the same ones that Elliot thought he could take down by hacking them. The illusion Elliot has been living in, despite his constant paranoia and nihilistic, cynical point of view, was to not understand that the revolution had already been bought and paid for by the system, for the system, in a plot twist similar in spirit to that of the Matrix franchise (The Wachowskis, 1999-2003). The cyberspace was never an escape: it was a trap.

\section{Conclusion}

54 Throughout this paper, we have tried to analyze the socio-cultural and political aspects of the confrontation between the digital and the physical world in four contemporary television series sharing America's most iconic megalopolis as a setting. Our goal was to open a discussion on how those worlds were represented, especially given the physical world produces a much more stable encyclopedia in the mind of the audience, compared to cyberspace, an elusive but nonetheless essential layer of reality.

We insist on the importance of approaching such analysis through the prism of possible worlds theory applied to fiction; we used Doležel's work on dyadic and hybrid structures, but we could have easily talked about the saturation and modalities of those worlds, especially since New York, a global city, is a well-defined space in the minds of many viewers - it is saturated with representations, and the shape and power dynamics of its urban spaces are known even by viewers who never actually experienced the city itself. Thus, every story told using New York as a setting sets up a priori interpretations of the narrative that the latter can choose to exploit in order to tackle more complex plotlines related to the city's power and place inside a global network.

It seems rather conventional that empiric genres such as procedurals and teen dramas treat the cyberspace as a sub-layer of reality, while science fiction series show it as a top layer, in terms of narrative focus and plot. The very different and disturbing structures observed in Person of Interest and Mr. Robot tells us a lot about their political discourse, with the former choosing to imagine a new divine realm harboring an 
existential threat, while the latter uses cyberspace to underline our own programming inside a corrupted political system. It is equally interesting to note that Gossip Girl and Elementary willingly accept the digital space as a given, a normal if elusive layer of our reality, so normal in fact that its dark side is not criticized beyond the needs of the plot. Broadcasted by the same network, CBS, Elementary and Person of Interest take the mass surveillance of New York citizens as granted, albeit the latter gives us a peek at how the system may see them, and how quickly it can turn against its creator: like the Frankenstein creature, New York City is seen as a body with two minds, undecided and potentially lethal. In Elementary, the morality of mass surveillance is never really questioned, because the characters consider it a tool among others, a necessary evil in a megalopolis such as New York, especially since, in their line of work, privacy is an obstacle to be circumvented.

While The CW's Gossip Girl does not threaten the system, no more than Gossip Girl threatens their queendom in the Upper East Side, the series still treats the violation of privacy as something potentially dangerous, but its series finale shows how the cyberspace was first and foremost a means of hacking 'analog social circles'. Mr. Robot is no less bleak and cynical, when it demonstrates how a corrupted system will trade both hope and despair to better manipulate its opponents, in a New York City that resemble the green-filtered megacity of The Matrix.

All four series have something in common: using cyberspace, they underline New York's transformation from "the city that never sleeps", into "the city that always watches".

\section{BIBLIOGRAPHY}

BORDWELL, David, Narration in the Fiction Film, Madison, University of Wisconsin Press, 1985.

CARROLL, Noel “Narrative Closure”, Philosophical Studies, No. 135, 2007, p. 2 [p. 1-15].

CONGER, Kate, "San Francisco Bans Facial Recognition Technology", The New York Times, May $14^{\text {th }}$, 2019, https://www.nytimes.com/2019/05/14/us/facial-recognition-ban-san-francisco.html.

DIBDIN, Emma, "9 Times Gossip Girl Was Even More Dramatic Behind The Scenes", Harper's Bazaar, September $19^{\text {th }}, 2017$, https://www.harpersbazaar.com/culture/film-tv/a12231760/ gossip-girl-scandals-behind-the-scenes/.

DOLEZEL, Lubomír, Heterocosmica: Fiction and Possible Worlds, Baltimore, London, Johns Hopkins University Press, 1998.

DUFOUR, Éric, Le Cinéma de science-fiction, Paris, Armand Colin, 2011, p. 189.

ECO, Umberto, Lector in fabula, Paris, Grasset, 2012 [1985].

FAVARD, Florent, "Watching with Ten Thousand Eyes: La Machine de Person of Interest est-elle un personnage ?", Otrante, No. 42, 2017 [p. 111-126]. 
GALLAGHER, Ryan and Henrik Moltke, “Titanpointe, the NSA's Spy Hub in New York, Hidden in Plain Sight", The Intercept, November $16^{\text {th }}, 2016$, https://theintercept.com/2016/11/16/the-nsasspy-hub-in-new-york-hidden-in-plain-sight.

GENETTE, Gérard, Discours du récit, Paris, Points, 2007 [1972, 1983].

HERMAN, David, Story Logic: Problems and Possibilities of Narrative, Lincoln, University of Nebraska Press, 2002.

HOTH, Stefanie, "The Female Voice in Sex and the City and Desperate Housewives: Voice-Over Narration in Contemporary American Television Series, in Gendered (Re)Visions: Constructions of Gender in Audiovisual Media, ed. Marion Gymnich, Kathrin Ruhl, Klaus Scheunemann, Göttingen, V\&R Unipress, 2010, p. 79-102.

MITTELL, Jason, Complex TV: The Poetics of Contemporary Television Storytelling, New York, New York University Press, 2015.

PEARSON, Roberta "Anatomising Gilbert Grissom: The Structure and Function of the Televisual Character", in Reading CIS: Crime TV Under the Microscope, ed. Michael Allen, London, I.B. Tauris, 2007.

RONCAYALO, Marcel, “Une géographie symbolique en devenir”, Le Débat, No. 80, 1994, p. 283-291. ROUSSEAU, Max "La ville comme machine à mobilité. Capitalisme, urbanisme et gouvernement des corps", Métropoles, No. 3, 2008, p. 181-206.

RYAN, Marie-Laure "Semantics, Pragmatics, and Narrativity: A Response to David Rudrum", Narrative, Vol. 14, No. 2, 2006, p. 188-196.

SASSEN, Saskia, "The Global City: Introducing a Concept", The Brown Journal of World Affairs, Vol. 11, No. 2, 2005.

SASSEN, Saskia, The Global City: New York, London, Tokyo, Princeton, Princeton University Press, 1991.

SUVIN, Darko "Estrangement and Cognition", in Speculations on Speculation: Theories of Science Fiction, ed. James Gunn, Matthew Candelaria, Lanham, Md, Scarecrow Press, 2005.

ZETTER, Kim, "How the real hackers behind Mr. Robot get it so right", Wired, July $15^{\text {th }}, 2016$, https://www.wired.com/2016/07/real-hackers-behind-mr-robot-get-right/.

\section{NOTES}

1. While Gossip Girl's blog posts are eventually attributed to a man, Dan Humphrey, we chose to address the blogger presenting as a woman with a gender-neutral pronoun, as Gossip Girl turns out to be multiple protagonists over time, and the blogger includes all their informers under the pseudonym in the season two finale; the choice of a woman voice was a red herring all along.

2. How I met Your Mother (CBS, 2005-2014), another television series set in New York City, turns it into a joke when the four protagonists, forever arguing about topics like "the most popular food" a few years before, now just check online - and get really bored - in S07E07.

3. See Saskia Sassen, The Global City: New York, London, Tokyo, Princeton, Princeton University Press, 1991.

4. Saskia Sassen, "The Global City: Introducing a Concept", The Brown Journal of World Affairs, Vol. 11 , No. 2, 2005, p. 41 [p. 27-43].

5. Sassen, p. 28.

6. Sassen, p. 29. The last quote is paraphrased. 
7. We admit being closer to Genette, who defines récit as the text itself, while syuzhet is, according to David Bordwell for example, "the actual arrangement and presentation of the fabula". Genette's récit encompasses more than just the order of events and allows us to tackle the architextual dimensions of the text - mainly, the episodic/serialized continuum and the generic influences. See David Bordwell, Narration in the Fiction Film, Madison, University of Wisconsin Press, 1985, p. 50; Gérard Genette, Discours du récit, Paris, Points, 2007 [1972, 1983], p. 15.

8. David Herman, Story Logic: Problems and Possibilities of Narrative, Lincoln, University of Nebraska Press, 2002, p. 13-14.

9. Lubomír Doležel, Heterocosmica: Fiction and Possible Worlds, Baltimore, London, Johns Hopkins University Press, 1998, p. 171 and following.

10. Umberto Eco imagines a novel starting with the sentence "Jean went to Paris"; while Jean might be an unknown character, the mere mention of Paris already opens a wide set of possibilities and forces the reader to recall everything she knows about this other iconic city. See Umberto Eco, Lector in fabula, Paris, Grasset, 2012 [1985], p. 163-164.

11. Marcel Roncayalo explains how, even with a city such as Paris, perceived first and foremost as a cultural and intellectual capital, these symbols and representations cannot be separated from the economic power that shapes them. See the interview with Roncayalo, "Une géographie symbolique en devenir", Le Débat, No. 80, 1994, p. 283 [p. 283-291].

12. Jason Mittell, Complex TV: The Poetics of Contemporary Television Storytelling, New York, New York University Press, 2015, p. 18.

13. Noel Carroll, "Narrative Closure”, Philosophical Studies, Vol. 135, No. 1, 2007, p. 2 [p. 1-15].

14. Doležel, p. 186-187.

15. Darko Suvin, "Estrangement and Cognition", in Speculations on Speculation: Theories of Science Fiction, ed. James Gunn and Matthew Candelaria, Lanham, Md, Scarecrow Press, 2005.

16. Sassen, p. 30.

17. See for example Stefanie Hoth, "The Female Voice in Sex and the City and Desperate Housewives: Voice-Over Narration in Contemporary American Television Series, in Gendered (Re)Visions: Constructions of Gender in Audiovisual Media, ed. Marion Gymnich, Kathrin Ruhl, Klaus Scheunemann, Göttingen, V\&R Unipress, 2010, p. 79-102.

18. Ryan Gallagher, Henrik Moltke, “Titanpointe, the NSA's Spy Hub in New York, Hidden in Plain Sight", The Intercept, November $16^{\text {th }}, 2016$, https://theintercept.com/2016/11/16/the-nsas-spyhub-in-new-york-hidden-in-plain-sight, consulted May $23^{\text {rd }}, 2020$.

19. Kate Conger, "San Francisco Bans Facial Recognition Technology", The New York Times, May $14^{\text {th }}$, 2019, https://www.nytimes.com/2019/05/14/us/facial-recognition-ban-san-francisco.html, consulted May $23^{\text {rd }}, 2020$.

20. Sherlock and Joan could thus be associated to the old-fashioned hacking culture born in the 1960s in the Massachusetts Institute of Technology. While it may be an unintended detail, it is interesting to note that the house of the protagonists, a "brownstone" made of brown sandstone typical of $19^{\text {th }}$ century East Coast architecture, could be seen as another link between New York City and the Boston area, where the MIT was established (in Cambridge): many academic fraternities and sororities are still housed in brownstones. The protagonists are roommates, one being the student of the other in earlier seasons, learning how to read people and find elegant and serendipitous solutions to their investigations.

21. Marie-Laure Ryan, "Semantics, Pragmatics, and Narrativity: A Response to David Rudrum", Narrative, Vol. 14, No. 2, 2006, p. 194 [p. 188-196].

22. Florent Favard, "Watching with Ten Thousand Eyes: La Machine de Person of Interest est-elle un personnage ?”, Otrante, No. 42, 2017 [p. 111-126].

23. Mittell, p. 137-141.

24. Max Rousseau, "La ville comme machine à mobilité. Capitalisme, urbanisme et gouvernement des corps”, Métropoles, No. 3, 2008, p. 182 [p. 181-206]. 
25. Roberta Pearson lists them as follows: behavior, physical characteristics, voice, interactions, environment, biography. Roberta Pearson, "Anatomising Gilbert Grissom: The Structure and Function of the Televisual Character", in Reading CIS: Crime TV Under the Microscope, ed. Michael Allen, London, I.B. Tauris, 2007.

26. Éric Dufour, Le Cinéma de science-fiction, Paris, Armand Colin, 2011, p. 189.

27. "We're in Gossip Girl country" says Vanessa right after she and Nate are photographed by a passerby, in S02E12.

28. It should be noted, though, that Jenny's fall from grace and outside the group of main protagonists was motivated by the actress musical and modeling career rather than a deliberate choice from the writing room. See Emma Dibdin, "9 Times Gossip Girl Was Even More Dramatic Behind The Scenes”, Harper's Bazaar, September 19th, 2017, https://www.harpersbazaar.com/ culture/film-tv/a12231760/gossip-girl-scandals-behind-the-scenes/, consulted May $23^{\text {rd }}, 2020$.

29. fsociety sets its headquarters on Coney Island, in an abandoned arcade supposedly haunted; in S02E03, Leslie Romero explains to fellow hacker Mobley that the arcade was thought by the previous owner to be "the nexus of all evil in the universe".

30. Exterior shots of E. Corp Headquarters use a specific landmark, the roofless tempietto on the plaza at the base of 135 East 57th Street, a circular structure mirrored, in S01E02, by Elliot encircled by businessmen, and metaphorically inverted when protesters encircle E. Corp during season three.

31. See for example Kim Zetter, "How the real hackers behind Mr. Robot get it so right", Wired, July 15th, 2016, https://www.wired.com/2016/07/real-hackers-behind-mr-robot-get-right/, consulted May $23^{\text {rd }}, 2020$.

\section{ABSTRACTS}

This article analyzes, within television series of the past twenty years, the tensions and power relations surrounding the private, intimate, and secret spheres, through the constant renegotiation of a dyadic structure linking the physical and the digital worlds. Can secrets be kept and people remain anonymous in a sprawling megalopolis?

This article focuses on four series that are different in genre and audience, but share two characteristics: these tensions and constant renegotiations are at the heart of their narratives, and they are all set in the iconic megalopolis that is New York City. Person of Interest (CBS, 2011-2016) features mass surveillance controlled by an artificially intelligent system; Gossip Girl (The CW, 2007-2012) pits the gilded youth of the Upper East Side against the eponymous blogger; Mr Robot (USA Network, 2015-2019) presents itself as a direct heir of the cyberpunk genre; finally, Elementary (CBS, 2012-2019) depicts a fragmented city held together by a ubiquitous digital clout that the investigators have to face up to.

Our comparative politico-spatial analysis of these four series will thus address contemporary representations of the complex relationships between the physical and the digital worlds.

Nous nous proposons d'explorer, au sein des séries des années 2000 et 2010, des confrontations et rapports de pouvoirs structurés autour du secret, de l'intime et du privé, marqués par la renégociation constante d'une structure dyadique: celle qui articule le monde physique au monde numérique. Peut-on encore cacher un secret, couvrir un délit ou un crime, vivre hors du système, a fortiori dans une mégalopole tentaculaire? 
Cet article se focalise sur quatre séries aux genres, chaînes et publics variés, qui possèdent deux points communs : elles mettent en avant cette renégociation au cœur de leur matrice, et se déroulent toutes dans une même ville iconique, riche d'un imaginaire puissant, international, imbibé par la pensée capitaliste : New York. Le corpus se compose de : Person of Interest (CBS, 2011-2016) et sa surveillance de masse orchestrée par une intelligence artificielle ; Gossip Girl (The CW, 2007-2012), qui confronte la jeunesse dorée de l'Upper East Side à la mystérieuse bloggeuse éponyme; Mr Robot (USA Network, 2015-2019), qui s'impose comme une héritière du genre cyberpunk; et enfin Elementary (CBS, 2012-2019), qui confronte Holmes et Watson à un New York fragmenté au sein duquel toutes les couches sociales ont pour terreau commun une empreinte numérique dans laquelle le duo d'enquêteur va souvent s'immerger.

$\mathrm{Au}$ travers de la comparaison de ces quatre œuvres, nous entendons mener, à travers une approche politico-spatiale du monde fictionnel, une réflexion sur la représentation des rapports contemporains entre les mondes physique et numérique.

\section{INDEX}

Mots-clés: narratologie, sociologie urbaine, mégalopole, cyberespace, New York

Keywords: narratology, urban sociology, megalopolis, cyberspace, New York City

\section{AUTHORS}

\section{JULIE AMBAL}

Julie Ambal, PhD in urban sociology, studies the imaginary of mobility in urban projects. She examines how our imaginations shape and inform the construction of cities, with a focus on the city of Bordeaux, France. She analyses the storytelling underlying urban projects, as well as the media coverage and dissemination of such stories. She has given several papers on urban and spatial imagination in audiovisual fictions.

Docteure en sociologie urbaine, Julie Ambal travaille sur la construction imaginaire de la mobilité dans les projets urbains, et s'intéresse à la façon dont nos imaginaires forment et informent la fabrication de la ville, plus particulièrement dans le cas de la métropole de Bordeaux. Elle analyse pour cela les mises en récit des acteurs des projets urbains, les dispositifs de médiatisations et de diffusion de ces récits. Elle a aussi donné plusieurs communications (articles à paraître) sur l'imaginaire de la ville et de l'espace dans les fictions audiovisuelles.

\section{FLORENT FAVARD}

Florent Favard, Associate Professor in Theory and Practice of Cinema, Audiovisual and Transmedia at IECA (Lorraine University, Nancy), focuses on the narrative complexity of contemporary science fiction television series and on SFF genres, using an approach centered on transmedial and contextualist narratology. He has published various papers and books on television series narratives (Écrire une Série TV, PUFR, 2019; Le Récit dans les séries de science-fiction, Armand Colin, 2018).

Florent Favard est maître de Conférences en Théorie et Pratique du Cinéma, de l'Audiovisuel et du Transmédia à l'IECA de Nancy (Université de Lorraine), Florent Favard travaille plus spécifiquement sur la complexité narrative des séries télévisées de science-fiction contemporaines et sur les genres de l'imaginaire, dans une perspective narratologique 
transmédiale et contextualiste. Il a notamment publié Écrire une série TV aux PUFR (2019) et Le Récit dans les séries de science-fiction chez Armand Colin (2018). 